\title{
Investigation of Anterior Tooth Dimensions and Color Distribution of Young Patients of Turkish Society
}

\author{
Merve Köseoğlu ${ }^{1}$, Nuran Yanıkoğlu ${ }^{2}$ \\ ${ }^{1}$ Department of Prosthodontics, Sakarya University, Sakarya, Turkey, ${ }^{2}$ Department of Prosthodontics, Atatürk University, Erzurum, \\ Turkey
}

\begin{abstract}
Aim: The objective of this study was to evaluate the maxillary and mandibular anterior tooth size and color distribution of young people of Turkish society.

Materials and method: In this study, we measured tooth dimensions and color distribution of totally 100 volunteers'. They were 18-25 years old. To ensure standardization, the measurement was made by the same researcher. Data was evaluated using SPSS 20.0 software. Descriptive data were presented as mean standard deviation. Kolmogorov-Smirnov test was used to assess the distribution of data. Independent samples t-test was used to compare boys' and girls' data.

Results: According to the results, widest teeth within both genders is the upper central teeth, the longest teeth are the lower canine teeth, narrowest teeth is lower central teeth, shortest teeth is lower central teeth. According to the color measurements; $52.38 \%$ of the female students have A shade; $21.42 \%$ have B shade; $26.20 \%$ has C shade. $46.5 \%$ of male students have A shade; $19 \%$ have B shade; $34.5 \%$ have $\mathrm{C}$ shade. $49 \%$ of the total population have A shade, $20 \%$ have B shade; $31 \%$ have $\mathrm{C}$ shade. Conclusions: When the width, the length and the width/length ratios of different colors were compared, the difference was not recorded as statistically significant.
\end{abstract}

Key Words: Maxillary anterior teeth, Mandibular anterior teeth, Width/Length ratio, Shade, Tooth dimension

\section{Clinical Implications}

Width/length ratio of every individual tooth and the ratio of maxillary anterior tooth dimensions in the arch is an important factor for dental esthetic and harmonious tooth alignment. Also, in order to provide esthetics in prosthetic restorations, selecting tooth color in harmony with the surrounding environment is necessary.

\section{Introduction}

The overall success of prosthetic tooth treatments is directly related to the condition in which patients have a satisfying smile. The esthetic result gained by prosthetic tooth treatments requires a comprehensive knowledge regarding oral esthetics $[1,2]$.

In order to achieve success in restorative treatments, the list which is first prepared in 1979 by Magne and Belser [3] and revised in 2002, which includes the esthetic parameters can be major guidance for clinicians. This list involves several objective and subjective parameters which are comprised of dental and gingival esthetics and also providing specific smile esthetics for individuals and the integration of an individual's smile to the face [3]. The most important objective dental criteria in this list are "the relative dimensions of teeth." It is considered that the width/length ratio of every individual tooth and the ratio of maxillary anterior tooth dimensions in the arch is an important factor for dental esthetic and harmonious tooth alignment [4]. Some researchers have reported that the value gained through the rating of maxillary and mandibular anterior teeth is supposed to be $5 / 4$ and this value can be a valuable aid for clinicians in choosing the tooth in edentalous patients [5]. Although there are a number of trials in the literature regarding natural tooth dimensions and the morphology of the tooth, the information available is contrary [3,6-9]. Since there are some differences between maxillary anterior tooth dimensions in relation to the race and gender, the studies involve only certain populations and the results are variable. Moreover in some populations, there is no correlation between gender and tooth morphology [7-14]. In the light of these results, it can be concluded that for every race or population, anterior tooth dimensions and ratios should be determined and the information gained by these results is valuable guidance for clinicians in restorative and prosthetic restorations in that population [15].

In order to provide esthetics in prosthetic restorations, selecting tooth color in harmony with the surrounding environment is necessary [16,17]. In dentistry tooth, color selection can be made through two techniques which are visual method and tooth color selection devices [18]. Tooth color selection via visual method can be made by tooth color scales [19]. The most commonly used scale currently is the Vita Classical Scale. Vita Classical Scale contains 4 different color tones which are specified as A, B, C, and D. Every tone has 4 subgroups according to their color density as $1,2,3$ and 4. The total number of color options is 16 [20]. The following criteria were important when determining the color: experience and age of the clinician, eye strain, whether color blindness or not, enlightening of the place, the type of the light which is used [21-23]. There are studies which examine the color distribution and the relation between gender and color in different races and also in Turkish population [18,24-29]. However, to our knowledge we couldn't find a comprehensive study in the literature regarding the relationship between tooth color, tooth dimensions, and gender.

Our null hypothesis is; there is no difference in color distribution according to gender in a society, there is a difference in maxillary central and canine tooth dimensions according to gender and there is no relation between a color distribution and tooth dimensions. 
In the present study, our purpose was to investigate the maxillary and mandibular tooth dimensions and color in students coming from the different regions of Turkey. This study will serve as a model to understand tooth dimensions and color distribution according to the gender in the young population who live in Turkey.

\section{Material and Methods}

This study has been applied on anterior teeth of 100 volunteer students, 58 males and 42 males age range between 18-25, who have been studying at the Ataturk University Dentistry Faculty. They come from different regions of Turkey. A student who has attended to the study were informed about the aim and the method of the study both written and orally. This study was approved by Atatürk University Faculty of Dentistry ethics committee. Including criteria in the study are followings:

- There should not be any missing mandibular and maxillary anterior teeth of patients

- Patients should not have any gingival or periodontal problems which damage a healthy relationship between teeth and gingiva

- Patients should not have any attrition, caries, fracture, restoration on maxillary and mandibular anterior teeth that cause any material loss

- There should not be diastema or crowding on maxillary and mandibular anterior teeth

- There should not be any orthodontic treatment back ground of patients

- Patients should not have any dental and facial deformations

- Patients should not have any bleaching treatment during the recent one year period

In order to maintain standardization of the study, measurements have been made by a single researcher. Patients were seated where his occlusal planum was parallel to the ground. Maxillary and mandibular teeth sizes were measured with a digital compass possessing $0.1 \mathrm{~mm}$ sensitivity (Absolute Digimatic Caliper, Mitutoyo Corporation, Aurora, IL, USA) and results were computerized (Figure 1). Length of maxillary and mandibular anterior teeth was measured parallel to long axle of teeth by referencing the incisal margin coronally and the gingival Zenit point apically. Width of teeth was calculated perpendicularly from the long axle of teeth, by measuring the longest distance between mesial and distal contact points.

In order to sustain standardization of the study, color measurement of teeth has been made by a single researcher in daylight with Vita-Classic Scale. Volunteers were requested for teeth brushing before color determination. During the color determination process, students were seated vertically to the unit, where their teeth were right across and at the same level with dentist's eyes.

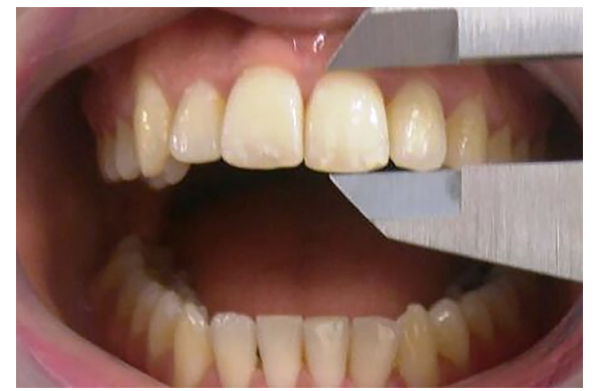

Figure 1. Maxillary and mandibular teeth size measurement.

During the color determination, patients were checked for not wearing colorful clothes, glasses, and lipstick. In order to minimize mistakes, the color measurement was repeated four weeks after the first color measurement with the same researcher under the same conditions. It was reported that there was no significant level of difference recorded between two measurements $(\mathrm{p}>0.05)$. Results of all measurements were computerized (Figure 2).

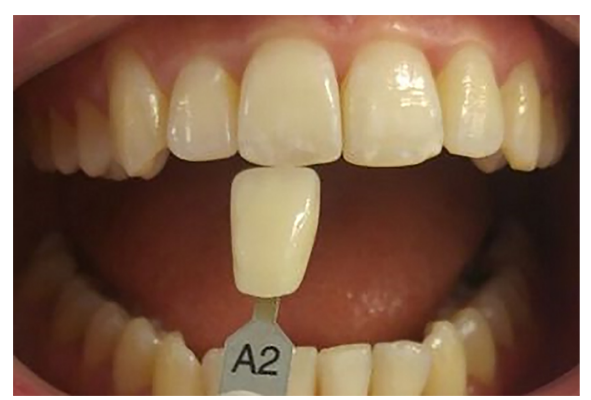

Figure 2. Color measurement of teeth.

SPSS 20.0 package program was used for assessing data. Definitive information has been provided as average \pm standard deviation. The Kolmogorov-Smirnov Test has been used for evaluating data distribution. T-test has been used in the process of comparing male-female student groups' data in independent samples. $\mathrm{p}<0.05$ was determined as significant in all analyses. Q Square Test was used when color distribution by gender was reviewed.

\section{Results}

42 female and 58 male students attended to the study. Table 1 shows the length, width and length/width ratio of maxillary and mandibular anterior teeth obtained from measurements of female and male students.

There was no significant difference found between genders when width, length and width/length ratio of right and left teeth were compared $(\mathrm{p}>0.05)$.

Based on outcomes of the study, for female attendants, maxillary right central incisor has the maximum width of 10 $\mathrm{mm}$ and the average width of $7.98 \mathrm{~mm}$, the maximum length of $11.50 \mathrm{~mm}$ and the average length of $9.49 \mathrm{~mm}$, the 
maximum length/width ratio of 1.26 and the average length/ width ratio of 0.84 .

Table 1. Length, width and length/width ratio of maxillary and mandibular anterior teeth.

\begin{tabular}{|c|c|c|c|c|}
\hline Female $(\mathrm{N}=42)$ & Minimum & Maximum & Mean & Standard deviation \\
\hline Upper central width/length & 0.65 & 1.26 & 0.84 & 0.1 \\
\hline Upper lateral width/length & 0.58 & 0.92 & 0.74 & 0.08 \\
\hline Upper canine width/length & 0.61 & 0.95 & 0.8 & 0.08 \\
\hline Lower central width/length & 0.46 & 0.83 & 0.62 & 0.07 \\
\hline Lower lateral width/length & 0.53 & 0.84 & 0.66 & 0.07 \\
\hline Lower canine width/length & 0.52 & 0.86 & 0.68 & 0.07 \\
\hline Upper central width & 6.5 & 10 & 7.98 & 0.71 \\
\hline Upper central length & 6.5 & 11.5 & 9.49 & 0.94 \\
\hline Upper lateral width & 5 & 7.3 & 6.02 & 0.61 \\
\hline Upper lateral length & 6.19 & 9.87 & 8.14 & 0.8 \\
\hline Upper canine width & 5.78 & 8.05 & 7.14 & 0.58 \\
\hline Upper canine length & 7 & 10.91 & 8.91 & 0.94 \\
\hline Lower central width & 4 & 5.5 & 4.86 & 0.36 \\
\hline Lower central length & 6 & 9.7 & 7.86 & 0.85 \\
\hline Lower lateral width & 4 & 6.29 & 5.34 & 0.43 \\
\hline Lower lateral length & 6.5 & 9.5 & 8.06 & 0.88 \\
\hline Lower canine width & 5 & 7.5 & 6.18 & 0.6 \\
\hline Lower canine length & 7 & 11.5 & 9.13 & 0.97 \\
\hline Male $(\mathrm{N}=58)$ & Minimum & Maximum & Mean & Standard Deviation \\
\hline Upper central width/length & 0.65 & 1.1 & 0.87 & 0.08 \\
\hline Upper lateral width/length & 0.64 & 0.96 & 0.78 & 0.07 \\
\hline Upper canine width/length & 0.6 & 0.95 & 0.8 & 0.08 \\
\hline Lower central width/length & 0.5 & 0.84 & 0.64 & 0.07 \\
\hline Lower lateral width/length & 0.51 & 0.85 & 0.67 & 0.08 \\
\hline Lower canine width/length & 0.55 & 0.83 & 0.66 & 0.06 \\
\hline Upper central width & 5 & 10.05 & 8.41 & 0.8 \\
\hline Upper central length & 7 & 11.93 & 9.64 & 1.03 \\
\hline Upper lateral width & 4 & 7.72 & 6.45 & 0.71 \\
\hline Upper lateral length & 5 & 9.69 & 8.19 & 0.89 \\
\hline Upper canine width & 6 & 9.5 & 7.5 & 0.72 \\
\hline Upper canine length & 7.71 & 11.13 & 9.31 & 0.91 \\
\hline Lower central width & 3 & 6.1 & 5.12 & 0.51 \\
\hline Lower central length & 5.9 & 9.88 & 8.05 & 0.88 \\
\hline Lower lateral width & 4 & 6.96 & 5.62 & 0.51 \\
\hline Lower lateral length & 6 & 10.23 & 8.33 & 0.89 \\
\hline Lower canine width & 5 & 7.88 & 6.58 & 0.55 \\
\hline Lower canine length & 7.6 & 12.5 & 9.91 & 1.04 \\
\hline
\end{tabular}


The maxillary right canine has the maximum width of 8.05 $\mathrm{mm}$ and the average width of $7.14 \mathrm{~mm}$, the maximum length of $10.91 \mathrm{~mm}$ and the average length of $8.91 \mathrm{~mm}$, the maximum length/width ratio of 0.95 and the average length/ width ratio of 0.80 . Mandibular left central incisor has the maximum width of $5.50 \mathrm{~mm}$ and the average width of 4.86 $\mathrm{mm}$, the maximum length of $9.70 \mathrm{~mm}$ and the average length of $7.86 \mathrm{~mm}$, the maximum length/width ratio of 0.83 and the average length/width ratio of 0.62 . Mandibular left canine has the maximum width of $7.50 \mathrm{~mm}$ and the average width of 6.18 $\mathrm{mm}$, the maximum length of $11.50 \mathrm{~mm}$ and the average length of $9.13 \mathrm{~mm}$, the maximum length/width ratio of 0.86 and the average length/width ratio of 0.68 .

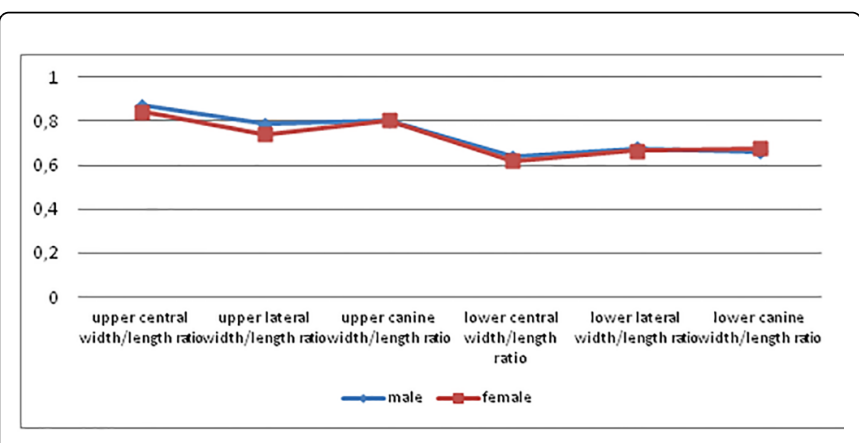

Figure 3. Anterior teeth's width/length ratio.

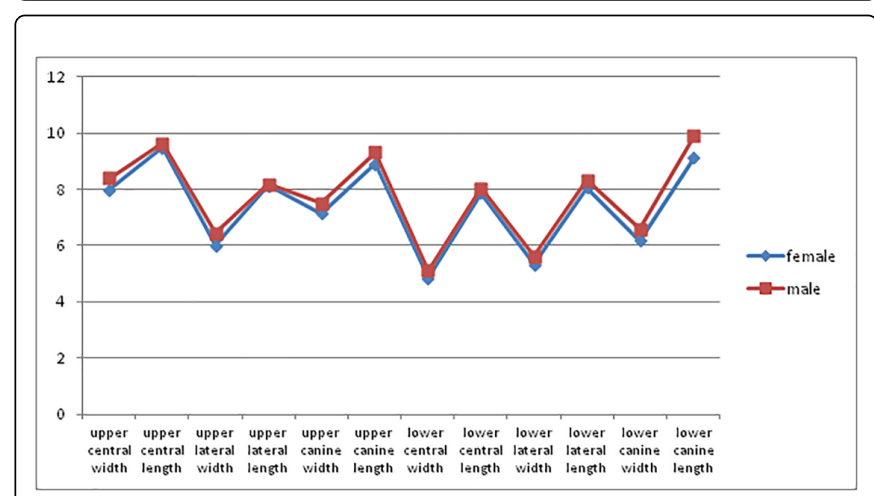

Figure 4. Anterior teeth's width and length measurements.

According to outcomes from the study (Figures 3 and 4), for male attendants, maxillary right central incisor has the maximum width of $10.05 \mathrm{~mm}$ and the average width of 8.41 $\mathrm{mm}$, the maximum length of $11.93 \mathrm{~mm}$ and the average length of $9.64 \mathrm{~mm}$, the maximum length/width ratio of 1.10 and the average length/width ratio of 0.87 . The maxillary right canine has the maximum width of $9.50 \mathrm{~mm}$ and the average width of $7.50 \mathrm{~mm}$, the maximum length of $11.13 \mathrm{~mm}$ and the average length of $9.31 \mathrm{~mm}$, the maximum length/width ratio of 0.95 and the average length/width ratio of 0.80 . Mandibular left central incisor has the maximum width of $6.10 \mathrm{~mm}$ and the average width of $5.12 \mathrm{~mm}$, the maximum length of $9.88 \mathrm{~mm}$ and the average length of $8.05 \mathrm{~mm}$, the maximum length/ width ratio of 0.84 and the average length/width ratio of 0.64 . Mandibular left canine has the maximum width of $7.88 \mathrm{~mm}$ and the average width of $6.58 \mathrm{~mm}$, the maximum length of $12.50 \mathrm{~mm}$ and the average length of $9.91 \mathrm{~mm}$, the maximum length/width ratio of 0.83 and the average length/width ratio of 0.66 .
In this study, the ratio of; sum of the widths of four maxillary incisor teeth to the sum of the widths of four mandibular incisor teeth was calculated 1.38 for males and 1.37 for females. The ratio of maxillary central incisor width to mandibular central incisor width was calculated 1.64 for males and 1.63 for females. These ratios are quite different than ratios suggested by some researchers which are $5 / 4$ $(\mathrm{p}<0.01)[5,30]$.

Table 2. Color distribution according to gender.

\begin{tabular}{|l|l|l|l|}
\hline Gender & A Color (\%) & B Color (\%) & C Color (\%) \\
\hline Female & $22(52.38 \%)$ & $9(21.42 \%)$ & $11(26.20 \%)$ \\
\hline Male & $27(46.5 \%)$ & $11(19 \%)$ & $20(34.5 \%)$ \\
\hline Total & $49(49 \%)$ & $20(20 \%)$ & $31(31 \%)$ \\
\hline
\end{tabular}

Based on results from the color measurement made by using Vita Classic Scale (Figure 5), 52.38\% of female students have A color, $21.42 \%$ have B color and $26.20 \%$ have C color. $46.5 \%$ of male students have A color, $19 \%$ have B color and $34.5 \%$ have $\mathrm{C}$ color. $49 \%$ of total population has $\mathrm{A}$ color, $20 \%$ have $\mathrm{B}$ color and $31 \%$ have $\mathrm{C}$ color (Table 2). Color $\mathrm{A}$ is the most observed color both in males and females whereas Color B is the least observed one. While colors observed in all participants regardless of gender, by using Vita Classic Scale, are A2 (26\%), A3 (13\%), B2 (13\%) and C2 (17\%); colors D1, D2, D3, and D4 could not be observed.

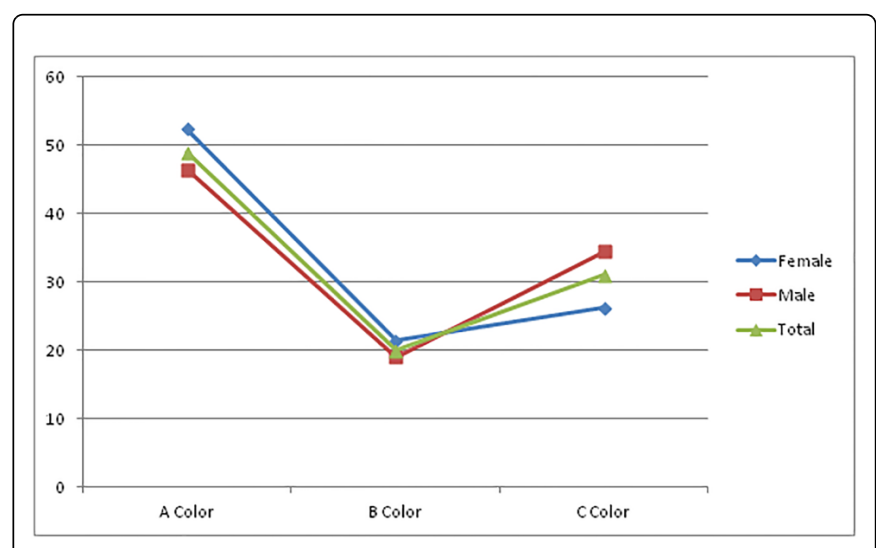

Figure 5. Female and male student's color distribution.

According to normality test applied, there was not any normal distribution of data recognized in male-female student sub-groups.

When widths, lengths and width/length ratio of teeth of males and females were compared, there was statistically significant difference recognized between; width/length ratio of maxillary lateral incisor, width of maxillary central incisor, width of maxillary lateral incisor, width of maxillary canine, length of maxillary canine, width of mandibular central incisor, width of mandibular lateral incisor, width and length of mandibular canine $(\mathrm{p}<0.05)$.

There was no statistically significant difference determined in color distribution in terms of gender $(p>0.05)$. When width, length and width/length ratio of different colors were compared, there was no statistically significant difference examined $(\mathrm{p}>0.05)$. 


\section{Discussion}

In this study, it has been figured out that teeth color distribution did not vary based on sex. Also, the size of maxillary central incisor and maxillary canine teeth differentiated according to sex. In addition, it has been recognized that there was no correlation between teeth size and color distribution. This entire hypothesis of the study has been accepted.

In Turkish society, there are several gene distributions observed due to its location and historical background of the country [14]. Therefore, different variations can be seen in dental and facial measurements. Despite these variations, knowledge about size and morphology of the anterior teeth leads dentists in anterior teeth restorations [15].

The early studies about dimensions of maxillary anterior teeth, which based on the anatomical crown length, were performed on extracted teeth [6-9]. Factors such as age, sex and race were not discussed in these studies. However, in recent studies, which based on the clinical crown length, intraoral or computer-assisted measurements were made $[5,9,10,12,14]$. In our study, the clinical crown length was calculated intraorally from apical to gingival zenith point [14].

Magne et al. [31]. have measured the anatomical crown length of maxillary teeth with and without abrasion in their study, which was performed in Switzerland on 146 extracted teeth. Excepting the abrasion, it has been observed that in terms of the width of teeth is as central incisor tooth $>$ canine tooth>lateral incisor tooth. Measurement in terms of teeth length is as non-abrasied central incisor $>$ non-abrasied canine $>$ abrasied central $>$ abrasied canine $>$ non-abrasied lateral $>$ abrasied lateral.

Tsukiyama et al. [1] study was performed with 264 extracted teeth from 2 different ethnic groups. They figured out that the maxillary anterior teeth width/length ratio of these ethnic groups was statistically different than each other. Moreover, they stated that the width of non-abrasied central incisor teeth and the length of both abrasied lateral incisor and canine teeth have been statistically different.

Isa et al. [32] in their study on 60 individuals aged between 18 to 36 from Malaysian and Chinese people have measured clinical crown lengths. They found that the average width of maxillary right central incisor was $8.54 \mathrm{~mm}$, the average width of left central incisor was $8.56 \mathrm{~mm}$; the average width of maxillary right lateral incisor was $7.09 \mathrm{~mm}$, the average width left lateral incisor was $7.07 \mathrm{~mm}$; the average width of maxillary right canine was $7.94 \mathrm{~mm}$ and the average width of the left canine was $7.90 \mathrm{~mm}$.

Condon et al. [33] have measured the height of the crown by using the digital composing stick in their study with a total of 109 individuals aged from 18 to 25 years in Ireland. They discovered that in males, canine teeth were $0.8 \mathrm{~mm}$ longer and $0.6 \mathrm{~mm}$ wider than females and central and lateral incisors were $0.5 \mathrm{~mm}$ wider in males. They could not find any difference in the length/width ratio of right and left incisor teeth.

Sterrett et al. [9] in their work performed on 71 individuals in Caucasian people; have come up with the result that in males, the width and length of maxillary central, lateral, and canine teeth are greater than those teeth of females.

Hasanreisoglu et al. [15] in their study conducted on 100 (50 females, 50 males) students at 22 years old in Turkish people, have seen that in maxillary central incisors and maxillary canines, males have statistically higher width and length rates than female students. In both genders, maxillary central teeth width was higher than lateral and canine teeth and maxillary lateral teeth width and length were similar.

In this study, the width of maxillary central incisors was higher than the widths of the maxillary lateral incisor and maxillary canine teeth but it wasn't significant $(\mathrm{p}>0.05)$.

Sah et al. [34] figured that the most stabilized reference for maxillary anterior teeth was the width/length ratio; because this ratio showed minimal variation in terms of teeth and sex comparison. Ward et al. [35] expressed that the width/length ratio of central incisor should be $78 \%$ in order to obtain dental aesthetics.

Sah et al. [34] in their experiment on 147 (82 females, 65 males) students between the ages of 18 and 25 in the Chinese society, measured the width/length ratio in maxillary central incisors $85.15 \%$ in males and $86.14 \%$ in females; the width/ length ratio in maxillary lateral incisors $84.74 \%$ in males and $84.32 \%$ in females; the width/length ratio in maxillary canine $86.4 \%$ in males and $87.14 \%$ in females.

Magne et al. [31] in their study on 146 extracted teeth in Switzerland measured the anatomical crown lengths of maxillary teeth with and without abrasion. They figured out that the width/length ratio; abrasied central incisor $(87 \%)>$ abrasied canine $(81 \%)$, abrasied lateral canine $(79 \%)>$ non-abrasied central incisor $(78 \%)>$ and non-abrasied canine $=$ non-abrasied lateral incisor $(73 \%)$.

Sterrett et al. [9] in their work performed on 71 Caucasian people figured that the width/length ratio of the central and lateral incisors was similar in both sexes; however, they stated that the width/length ratio of canine teeth was higher in females than in males.

Hasanreisoglu et al. [15] in their work performed on 100 (50 females, 50 males) students at 22 years-old from Turkish group, the ratio of maxillary central incisor width/length was $88.7 \%$ in male students and $91.2 \%$ in female students. The maxillary lateral incisor width/length ratio was $82.1 \%$ for male students and $83.4 \%$ for female students; the ratio of maxillary canine width/length was $83.4 \%$ for male students and $87.3 \%$ for female students.

They explained that there was no statistically significant difference observed based on sex in the width/length ratio of the maxillary central and lateral incisors, however, there was a statistically significant difference in terms of gender in the width/length ratio of maxillary canine.

In this study, it was measured that the width/length ratio of the maxillary central incisor was $87.1 \%$ for male students and $84.2 \%$ for female students, the width/length ratio of the maxillary lateral was $78.5 \%$ in male students, $73.9 \%$ in female students, the width/length ratio of maxillary canine incisor was $80.5 \%$ in male students, $80.4 \%$ in female students, the width/length ratio of mandibular central incisor was $63.8 \%$ in 
male students, $62 \%$ in female students, the width/length ratio of mandibular lateral incisor was $67.5 \%$ for male students and $66.5 \%$ for female students, the width/length ratio of mandibular canine was $66.3 \%$ for male students and $67.6 \%$ for female students. In this study, there was a statistically significant difference recorded between sexes in the width/ length ratio of the maxillary lateral incisor, but no statistically significant difference recorded among genders in the width/ length ratio of other teeth.

Koca et al. [36] who studied on 98 Turkish individuals aged between 18 and 40, investigated the dimensional ratios of maxillary and mandibular anterior teeth irrespective of genders. They calculated the ratio of the total widths of maxillary four incisor teeth to the total widths of mandibular four incisor teeth was 1.39. Also, they established that the ratio of the width of maxillary central incisor to the width of mandibular central incisor had an average value of 1.65.

However, in this study, the ratio of the sum of the widths of four mandibular incisor teeth to the sum of the widths of four maxillary incisor teeth was 1.38 in males and 1.37 in females. The ratio of the width of the maxillary central tooth to the width of mandibular central tooth was 1.64 in males and 1.63 in females.

Despite the fact that values obtained in both studies were close to each other, these values are still quite different from the value of $5 / 4$ which was desired by researchers $[5,30]$.

In this study, teeth color which is a significant factor in sustaining aesthetics in dental treatments has been investigated. Ongul et al. [18] studied on maxillary central, lateral and canine teeth of a total of 164 Turkish individuals aged between 18-22. They expressed that the teeth colors, determined by using Vita Classical color scale in all individuals, were mostly $\mathrm{B} 2, \mathrm{C} 2$ and $\mathrm{C} 3$, and also in their measurements, D1; D3; D4 and C4 colors were not detected.

Eroglu et al. [29] concluded in their study, which conducted on healthy and unrestored maxillary and mandibular central incisors of 475 Turkish patients, that the highest percentage of color code distributions were B2 (13.9), B3 (12.4), C3 (12.2), A4 (10.5). The lowest percentage of color code distribution were A3 (1.7), B3 (1.3), D3 (1.1), D4 (1.1) and D1 was not observed at all.

Akcaboy et al. [37], have worked on teeth color distribution based on geographic region, age, and sex in their study of 700 patients in Turkey. The most commonly observed colors in Turkey were A2 (18.36\%); A3 (18.14\%) and B3 (11.59\%) and the least detected color was D4 $(1.12 \%)$. The most common teeth colors seen in females were A2 (22.32\%), A3 (19.92\%) and B2 (10.44\%) and the most common teeth colors observed in males were A3 (16.26\%), A2 (14.14\%) and B3 (14\%).

In this study, the most frequently detected colors in all individuals are A2 (26\%), A3 (13\%), B2 (13\%) and C2 $(17 \%)$. D1, D2, D3 and D4 colors are not observed in our measurements. In females, A2 (33.3\%) and B2 (16.6\%) are the most common colors and C2 (22.4\%) and A2 (20.6\%) are the most detected colors in males.

\section{Conclusion}

According to the results obtained from the study:

1. There was no statistically significant difference recorded in both genders while comparing the width, the length and the width/length ratios of right and left teeth $(\mathrm{p}>0.05)$

2. The value obtained from the ratio of the sum of the widths of four maxillary incisors to the sum of the widths of the four mandibular incisor teeth was 1.38 in males and 1.37 in females

3. The ratio of the width of maxillary central incisors to the width of mandibular central incisors was in a value of 1.64 in males and 1.63 in females

4. In male students, the width of maxillary central incisor, the width of maxillary lateral incisor, the width and the length of maxillary canine, the width of mandibular central incisor, the width of mandibular lateral incisor and the width and length of mandibular canine were higher than female students and the difference between the dimensions was statistically significant $(\mathrm{p}<0.05)$. In both genders, the width of maxillary central incisors were larger than the width of maxillary lateral incisors and maxillary canine teeth

5. While there was a statistically significant difference $(p<0.05)$ among genders in the ratio of the width/length of the maxillary lateral incisor, there was no statistically significant difference observed in the width/length ratio of other teeth based on genders $(\mathrm{p}>0.05)$

6. There was no statistically significant difference recognized in the distribution of colors in terms of genders $(\mathrm{p}>0.05)$

When the width, the length and the width/length ratios of different colors were compared, the difference was not recorded as statistically significant.

\section{Compliance with Ethical Standards}

\section{Conflict of interest}

Author Koseoglu declares that he has no conflict of interest. Author Yanikoglu declares that he has no conflict of interest.

\section{Funding}

The work was supported by Atatürk University, Faculty of Dentistry, Department of Prosthodontics, in Erzurum, Turkey.

\section{Ethical approval}

This article does not contain any studies with human participants or animals performed by any of the authors. All applicable international, national, and/or institutional guidelines for the care and use of animals were followed. All procedures performed in studies involving human participants were in accordance with the ethical standards of the institutional and/or national research committee and with the 1964 Helsinki declaration and its later amendments or comparable ethical standards. 


\section{Informed consent}

For this type of study, formal consent is not required. Informed consent was obtained from all individual participants included in the study.

\section{References}

1. Tsukiyama T, Marcushamer E, Griffin TJ, Arguello E, Magne $\mathrm{P}$, et al. Comparison of the anatomic crown width/length ratios of unworn and worn maxillary teeth in Asian and white subjects. The Journal of Prosthetic Dentistry. 2012; 107: 11-16.

2. Belser U. Esthetics checklist for the fixed prosthesis. Part II: Biscuit-bake try-in. In: Scharer P, Rinn L, Kopp F, editors. Esthetic guidelines for restorative dentistry. Chicago: Quintessence. 1982: 188-192.

3. Magne $P$, Belser U. Bonded porcelain restorations in the anterior dentition: A biomimetic approach. In: Magne P, Belser U, editors. Natural oral esthetics. Chicago: Quintessence. 2002: 57-96.

4. Ward DH. Proportional smile design using the recurring esthetic dental (red) proportion. Dental Clinics of North America. 2001; 45: 143-154.

5. Sears V. Selection of anterior teeth for artificial dentures. Journal of the American Dental Association. 1941; 28: 928-935.

6. Ash M. Wheeler's atlas of tooth form. 5th ed. Philadelphia: Saunders. 1984: 24-25.

7. Chiche G, Pinault A. Esthetics of anterior fixed prosthodontics. Chicago: Quintessence. 1994.

8. Gillen RJ, Schwartz RS, Hilton TJ, Evans DB. An analysis of selected normative tooth proportions. The International Journal of Prosthodontics. 1994; 7: 410-417.

9. Sterrett JD, Oliver T, Robinson F, Fortson W, Knaak B, et al. Width/length ratios of normal clinical crowns of the maxillary anterior dentition in man. Journal of Clinical Periodontology. 1999; 26: 153-157.

10. Lavelle CL. Maxillary and mandibular tooth size in different racial groups and in different occlusal categories. American Journal of Orthodontics. 1972; 61: 29-37.

11. Richardson ER, Malhotra SK. Mesiodistal crown dimension of the permanent dentition of American Negroes. American Journal of Orthodontics. 1975; 68: 157-164.

12. Sherfudhin H, Abdullah MA, Khan N. A cross-sectional study of canine dimorphism in establishing sex identity: comparison of two statistical methods. Journal of Oral Rehabilitation. 1996; 23: 627-631.

13. Owens EG, Goodacre CJ, Loh PL, Hanke G, Okamura M, et al. A multicenter interracial study of facial appearance. Part 2: A comparison of intraoral parameters. The International Journal of Prosthodontics. 2002; 15: 283-288.

14. Iscan MY, Kedici PS. Sexual variation in bucco-lingual dimensions in Turkish dentition. Forensic Science International. 2003; 137: 160-164.

15. Hasanreisoglu U, Berksun S, Aras K, Arslan I. An analysis of maxillary anterior teeth: facial and dental proportions. The Journal of Prosthetic Dentistry. 2005; 94: 530-538.

16. Bayindir F, Bayindir Y, Wee A. Gingival color match and gingival shade guides in restorative dentistry. Journal of Dental Faculty of Atatürk University. 2010; 3: 38-43.

17. Yilmaz S, Seker E, Ozan O, Meric G, Yilmaz B. Evaluation of success of dentist and dental technician color match by using VITA Toothguide 3D-Master Scale. Cumhuriyet Dental Journal. 2011; 14: 92-100.

18. Ongul D, Celik B, İlbey D, Sermet B. Investigation of tooth color distribution of young patients of turkish society. Journal of Istanbul University. 2013; 47: 30-40.
19. Goodkind RJ, Loupe MJ. Teaching of color in predoctoral and postdoctoral dental education in 1988. The Journal of Prosthetic Dentistry. 1992; 67: 713-717.

20. Paravina RD. Performance assessment of dental shade guides. Journal of Dentistry. 2009; 37: 15-20.

21. Lasserre JF, Pop-Ciutrila IS, Colosi HA. A comparison between a new visual method of color matching by intraoral camera and conventional visual and spectrometric methods. Journal of Dentistry. 2011; 39: 29-36.

22. Barna GJ, Taylor JW, King GE, Pelleu GB Jr. The influence of selected light intensities on color perception within the color range of natural teeth. The Journal of Prosthetic Dentistry. 1981; 46: 450-453.

23. Sorensen JA, Torres TJ. Improved color matching of metalceramic restorations. Part I: A systematic method for shade determination. The Journal of Prosthetic Dentistry. 1987; 58: 133-139.

24. Hasegawa A, Ikeda I, Kawaguchi S. Color and translucency of in vivo natural central incisors. The Journal of Prosthetic Dentistry. 2000; 83: 418-423.

25. Yilmaz S, Seker E, Ozan O. Evaluation of the natural tooth color of young Turkish population in Northern Cyprus: A pilot study. Cumhuriyet Dental Journal. 2011; 14: 10-20.

26. Goodkind RJ, Schwabacher WB. Use of a fiber-optic colorimeter for in vivo color measurements of 2830 anterior teeth. The Journal of Prosthetic Dentistry. 1987; 58: 535-542.

27. Eiffler C, Cevirgen E, Helling S, Zornek J, Pritsch M, et al. Differences in lightness, chroma, and hue in the anterior teeth of quinquagenarians and septuagenarians. Clinical Oral Investigations. 2010; 14: 587-591.

28. Al-Saleh S, Tashkandi E. Three dimensional color coordinates of natural teeth in a sample of young Saudis: a pilot study. Saudi Dental Journal. 2007; 19: 97-100.

29. Eroglu E, Kucukesmen H, Uluhan B. Determination of tooth color distribution in the patients who appealed to clinics of prosthetic dentistry of S.D.U. SDÜ Tip Fakültesi Dergisi. 2007; 14: 28-31.

30. Lejoyeux J. Traitement de I' edutation totale. Paris Maloine. 1985: 121-122.

31. Magne P, Gallucci GO, Belser UC. Anatomic crown width/ length ratios of unworn and worn maxillary teeth in white subjects. The Journal of Prosthetic Dentistry. 2003; 89: 453-461.

32. Isa ZM, Tawfiq OF, Noor NM, Shamsudheen MI, Rijal OM. Regression methods to investigate the relationship between facial measurements and widths of the maxillary anterior teeth. The Journal of Prosthetic Dentistry. 2010; 103: 182-188.

33. Condon M, Bready M, Quinn F, O'Connell BC, Houston FJ, et al. Maxillary anterior tooth dimensions and proportions in an Irish young adult population. Journal of Oral Rehabilitation. 2011; 38: 501-508.

34. Sah SK, Zhang HD, Chang T, Dhungana M, Acharya L, et al. Maxillary anterior teeth dimensions and proportions in a central mainland Chinese population. Chinese Journal of Dental Research. 2014; 17: 117-124.

35. Ward DH. A study of dentists' preferred maxillary anterior tooth width proportions: comparing the recurring esthetic dental proportion to other mathematical and naturally occurring proportions. Journal of Esthetic and Restorative Dentistry. 2007; 19: 324-337.

36. Koca G, Dinckal N. Dimensional ratios of maxillary and mandibular anterior teeth. Ege Üniversitesi Dişhekimliği Fakültesi Dergisi. 1996; 17: 1-3.

37. Akcaboy C, Nalbant D, Demirkoprulu H, Dinckal N, Nigiz $\mathrm{R}$, et al. General distribution of natural tooth color in turkey. The Journal of Dental Faculty of Atatürk University. 1994; 4: 1-9. 